from which to make decisions concerning the best way of using PUVA in those who are considered suitable for this form of treatment.

This study was sponsored by the Medical Research Council. We thank especially the working group of the MRC for their constant help and advice. The 8-methoxypsoralen (methoxsalen) tablets were donated by Stiefel Laboratories (UK) Ltd. We also thank Professor G Rose and Dr M Corbett for statistical advice, S Roubo, P Elliot, A Whiteley, and P Lamb for nursing help, and M Smith and N Vella Briffa for secretarial work.

\section{References}

${ }^{1}$ Rogers S, Greaves M, Marks J, Shuster S, Vella Briffa D, Warin A. Comparison of photochemotherapy and dithranol in the treatment of chronic plaque psoriasis. Lancet $1979 ; \mathrm{i}: 455-8$.

2 Colton T. Longitudinal studies and the use of the life table. In: Statistics in medicine. Boston, Massachusetts: Little, Brown and Co (Inc), 1974:237-50.

${ }^{3}$ Seville RH. Simplified dithranol treatment for psoriasis. $\mathrm{Br} \mathcal{F}$ Dermatol $1975 ; 93: 205 \div 8$.

(Accepted 18 December 1980)

\title{
Algorithmic method for assessing urinary incontinence in elderly women
}

\author{
P HILTON, S L STANTON
}

\begin{abstract}
In young patients the assessment of urinary incontinence is based increasingly on the results of complex urodynamic investigations. The value of such techniques in the elderly, however, is as yet unproved. Based on the clinical and urodynamic findings in 100 incontinent elderly women an algorithmic method for managing such patients was devised. A retrospective study comparing the algorithmic outcome with the results of standard urodynamic assessment showed that $60 \%$ of invasive investigations could be avoided by this method with minimal loss of diagnostic accuracy.
\end{abstract}

\section{Introduction}

The incidence of urinary incontinence in the elderly has been assessed as between $1.6 \%$ and $42 \%,{ }^{1}$ and its costs to the individual and to the Health Service are considerable. Wholesale investigation of urinary incontinence, however, is justified only if it can be shown to provide at minimal risk an accurate diagnosis which could not be obtained by simpler means; and if based on that diagnosis a rational and effective treatment could be provided. Urodynamic investigations undoubtedly provide an accurate diagnosis in young patients, though their application to the elderly is rarely reported. That effective treatment is available for correctly diagnosed urinary incontinence in the elderly is questionable. Nevertheless, in cases of incompetence of the urethral sphincter (genuine stress incontinence) Stanton and Cardozo $^{2}$ reported cures in $75 \%$ of patients over 65 years of age who were treated by colposuspension.

The risks from urodynamic investigation are small; Walter and Vejlsgaard ${ }^{3}$ reported urinary infection in only $2 \%$ of patients after investigation. Of perhaps greater importance is the discomfort and distress caused to some patients, which may be considerable in the elderly, particularly those with other

Urodynamic Unit, Department of Obstetrics and Gynaecology, St George's Hospital Medical School, London SW17 ORE

P HILTON, MB, MRCOG, clinical research fellow

St George's Hospital Medical School, London SW17 ORE

S L STANTON, FRCS, MRCOG, honorary senior lecturer physical disease or intellectual impairment. With these factors in mind we proposed to define a more efficient method of investigating urinary incontinence in elderly women.

\section{Patients and methods}

We studied 100 women aged $65-93$ years (mean $74 \cdot 6$ years) who were referred to the urodynamic unit for urinary incontinence. They were investigated according to our usual practice. On referral a standardised data sheet including general medical, neurological, gynaecological, and urological history and examination was completed. ${ }^{4}$ Peak urine flow rate was determined using either a rotating disc flow meter or a modified von Garrelts apparatus. Detrusor function was investigated by twin-channel subtracted water cystometry at a rapid filling rate (roughly $100 \mathrm{ml} / \mathrm{min}$ ) in the supine position. The effect of passive postural change on detrusor pressure was assessed and simultaneous voiding pressures and flow rates recorded where practicable (56 patients). In 30 patients whose general condition was considered to be adequate videocystourethrography was performed in place of cystometry. Urethral closure pressure profile measurements were recorded using a dual sensor microtransducer catheter ${ }^{5}$ in 22 patients. In one patient whose incontinence was not confirmed by the above procedures a Urilos nappy test ${ }^{6}$ was performed.

On completion of these investigations a diagnosis was made for each patient. Where mixed diagnoses were considered-for example, difficulty in voiding owing to outflow obstruction associated with detrusor instability - the patient was assigned to the diagnosis that warranted primary treatment.

Methods, definitions, and units conform to the standards proposed by the International Continence Society. ${ }^{10}$ Frequency is the passage of urine two-hourly or seven times or more during waking hours, and nocturia the arousal from sleep to void on two or more occasions each night.

\section{Results}

Table I lists the final diagnoses in the 100 women, established on the basis of clinical and urodynamic assessments. Table II gives the symptoms in relation to these diagnoses. Though stress incontinence was common in women with an incompetent urethral sphincter $(63 \%)$ and less common in those with detrusor instability (33\%), this symptom was also noted by $49 \%$ of the group as a whole and $77 \%$ of women with voiding difficulties. Symptoms usually associated with detrusor instability in younger patients-urgency, urge incontinence, enuresis, and both diurnal and nocturnal frequency - were common in all diagnostic categories. Of the symptoms associated with voiding difficulties, poor urinary stream had the best 
correlation; nevertheless, $30 \%$ of all patients complained of this symptom.

Table III shows the incidences of various gynaecological, neurological, and urological signs. Evidence of significant atrophic vaginitis was common, predominantly in patients with an incompetent urethral sphincter. Vaginal prolapse was surprisingly uncommon. The association between upper motor-neurone lesions and detrusor instability is well established and was confirmed in our series, 12 of the 19 patients with clinically evident lesions being in this diagnostic category.

Thirteen patients had residual volumes exceeding $100 \mathrm{ml}$. In 10 this was evident on abdominal palpation (300-1250 ml), and in the remainder the residual volume was not considered important enough in determining symptoms to warrant primary treatment. Stress incontinence in women with voiding difficulties was shown only in association with palpable bladder enlargement. Of the 14 patients with voiding difficulties, three were thought to have infravesical obstruction (one associated with uterovaginal prolapse); three showed no evidence of detrusor activity at any stage and voided only by abdominal straining; and eight showed evidence of reduced bladder compliance on filling cystometry. Of this last group, four were unable to void during the investigation, three voided entirely by straining, and one voided by normal albeit unsustained detrusor contraction. In all cases, however, treatment was determined by the degree of incontinence and the patient's general fitness; a vesical or infravesical cause was not considered.

Stress incontinence was shown in 10 of the 39 patients with detrusor instability, though in no case were cough-induced detrusor contractions with consequent urinary leakage evident. Of patients with incompetence of the urethral sphincter, only 11 (37\%) showed the physical sign of stress incontinence in the supine position after micturition. In the remainder it was demonstrated at bladder capacity standing or, in one case, only on extended assessment by an electronic nappy test.

Table IV notes the incidences of abnormal urodynamic features. In 37 of the 39 patients in whom detrusor instability was found it was evident on supine filling; postural change led to detection of

TABLE I-Urodynamic diagnoses in 100 elderly women

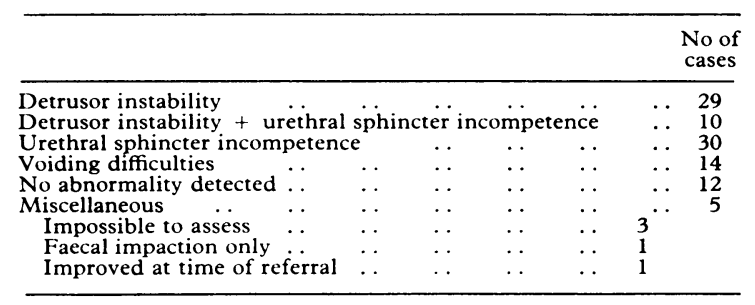

only two additional cases. Impairment of peak urine flow rate (less than $15 \mathrm{ml} / \mathrm{s}$ ) was found in 33 patients, though in only 14 was this considered to be the main abnormality. In the remainder, though follow-up was incomplete, patients with detrusor instability or incompetence of the urethral sphincter in association with a low flow rate obtained a subjective response to treatment at three months equal to that obtained by patients with normal flow rates.

TABLE IV-Percentage incidences of urodynamic features by diagnosis

\begin{tabular}{|c|c|c|c|c|c|}
\hline \multirow{2}{*}{ Diagnosis } & \multicolumn{3}{|c|}{ Unstable cystometry* } & \multirow{2}{*}{$\begin{array}{c}\text { Reduced } \\
\text { urine } \\
\text { flow } \\
\text { rate† }\end{array}$} & \multirow{2}{*}{$\begin{array}{c}\text { Reduced } \\
\text { urethral } \\
\text { pressure }\end{array}$} \\
\hline & & Supine & Standing & & \\
\hline \multirow{4}{*}{$\begin{array}{l}\text { Detrusor instability }(n=29) \\
\text { Detrusor instability and urethral } \\
\text { sphincter incompetence }(n=10) \\
\text { Urethral sphincter incompetence } \\
\text { ( } n=30) \\
\text { Voiding difficulties }(n=14) \cdots \\
\text { No abnormality detected }(n=12)\end{array}$} & . & 93 & 7 & 31 & $0(0 / 1)$ \\
\hline & .. & 100 & 0 & 33 & \\
\hline & . & 0 & 0 & 10 & $86(12 / 14)$ \\
\hline & $\therefore$ & $\begin{array}{r}57 \\
0\end{array}$ & $\begin{array}{l}0 \\
0\end{array}$ & $\begin{array}{c}100 \S \\
16\end{array}$ & $\begin{array}{l}0(0 / 5) \\
0(0 / 2)\end{array}$ \\
\hline All patients assessed $(n=95)$ & & 47 & 2 & 33 & $55(12 / 22)$ \\
\hline
\end{tabular}

* Pressure rise on bladder filling or postural change exceeding $15 \mathrm{~cm}$ water.

+Peak urine flow rate below $15 \mathrm{ml} / \mathrm{s}$.

+ Negative closure pressure during stress urethral pressure profile.
§Includes four patients unable to void during investigations.

Seventeen patients had infected urine at the time of referral, and in six this was associated with palpable bladder enlargement. Eight showed faecal impaction when first seen, which in four was associated with voiding difficulties.

These findings suggest that, apart from confirming the complaint of incontinence and giving some guide to its severity, the clinical history is of limited value in establishing the cause of urinary incontinence in the elderly. We do not, of course, decry its use, since an accurate knowledge of a patient's pattern of incontinence may be of considerable value in defining the most rational treatment plan.

A palpable bladder indicates a significant voiding difficulty. Though the patient may complain of the symptom and show evidence of stress incontinence, treatment should be directed towards the voiding difficulty in the first instance. Stress incontinence most commonly indicates incompetence of the urethral sphincter, though this may coexist with detrusor instability. The sign should be sought with the patient standing with a full bladder. Culture of a midstream specimen of urine and rectal examination should form an early part of the assessment of urinary incontinence in the elderly.

Based on these considerations an algorithmic method for investigating urinary incontinence in the elderly woman was developed (figure).

TABLE II-Percentage incidences of symptoms related to urodynamic diagnoses*

\begin{tabular}{|c|c|c|c|c|c|c|c|c|c|c|}
\hline Diagnosis & & $\begin{array}{c}\text { Stress } \\
\text { incontinence }\end{array}$ & Urgency & $\begin{array}{c}\text { Urge } \\
\text { incontinence }\end{array}$ & Enuresis & Frequency & Nocturia & $\begin{array}{l}\text { Strain } \\
\text { to void }\end{array}$ & Poor stream & $\begin{array}{l}\text { Incomplete } \\
\text { emptying }\end{array}$ \\
\hline $\begin{array}{l}\text { Detrusor instability }(\mathrm{n}=29) \\
\text { Detrusor instability }+ \text { urethral sphincter }\end{array}$ & $\therefore$. $\ldots$ incompetence & 33 & 84 & 80 & 46 & 68 & 52 & 0 & 9 & 4 \\
\hline $\begin{array}{l}\text { Detrusor instability }+ \text { urethral sphincter } \\
\quad(n=10) \\
\text { Urethral sphincter incompetence }(n=30) \\
\text { Voiding difficulty }(n=14) \\
\text { No abnormality detected }(n=12) \ldots \\
\text { Miscellaneous }(n=5)\end{array}$ & 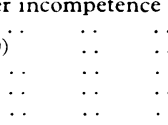 & $\begin{array}{l}43 \\
63 \\
77 \\
20 \\
33\end{array}$ & $\begin{array}{r}100 \\
70 \\
58 \\
90 \\
33\end{array}$ & $\begin{array}{l}71 \\
57 \\
58 \\
90 \\
33\end{array}$ & $\begin{array}{r}60 \\
30 \\
62 \\
0 \\
50\end{array}$ & $\begin{array}{l}67 \\
67 \\
62 \\
70 \\
40\end{array}$ & $\begin{array}{l}67 \\
50 \\
38 \\
50 \\
60\end{array}$ & $\begin{array}{r}0 \\
10 \\
43 \\
10 \\
0\end{array}$ & $\begin{array}{l}38 \\
30 \\
72 \\
20 \\
25\end{array}$ & $\begin{array}{r}38 \\
33 \\
33 \\
20 \\
0\end{array}$ \\
\hline All patients $(n=100)$ & $\ldots$ & 49 & 76 & 68 & 39 & 65 & 51 & 10 & 30 & 23 \\
\hline
\end{tabular}

*Disparities in some figures resulted from patients' inability to answer all questions.

TABLE III-Percentage incidences of physical signs related to diagnoses

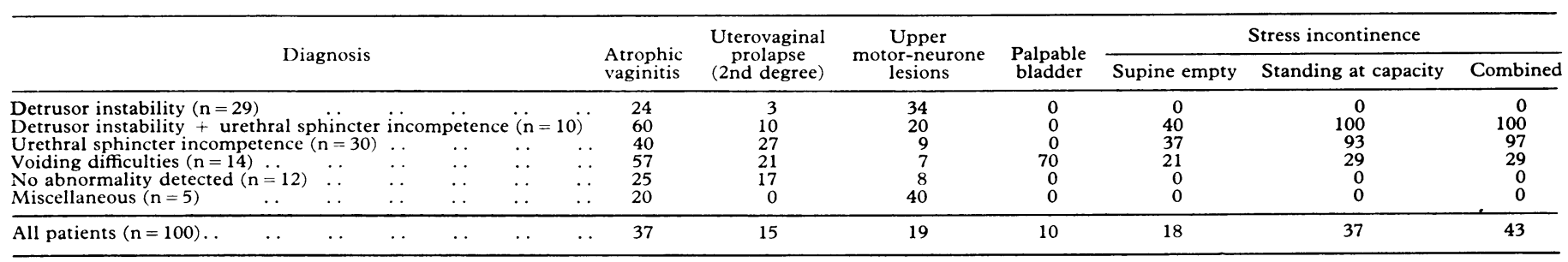




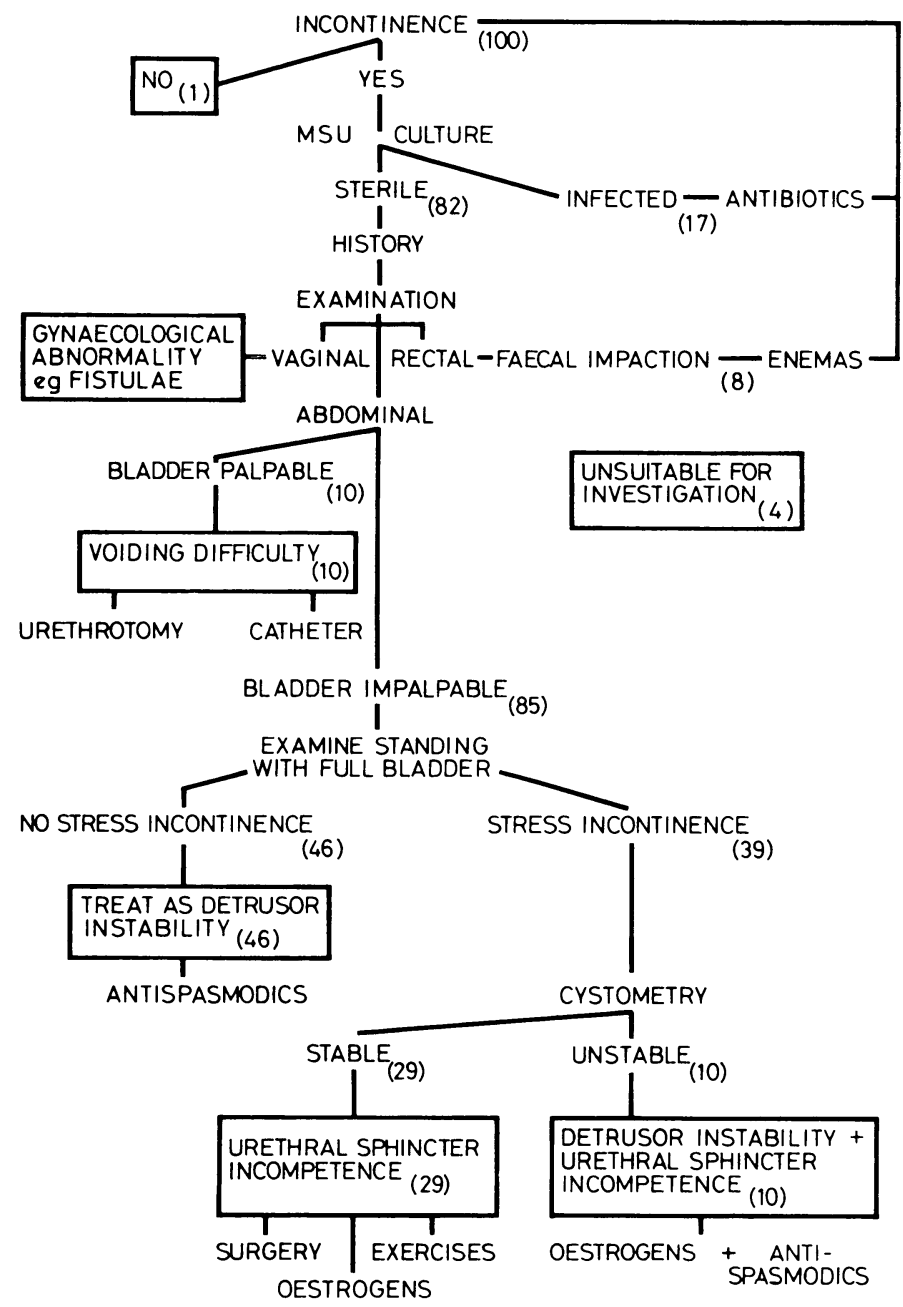

Algorithm for assessment of urinary incontinence in elderly women. Figures in parentheses are numbers of patients who followed each route when algorithm was applied to 100 patients retrospectively. MSU = Midstream specimen of urine.

\section{EVALUATION OF ALGORITHM}

Had the algorithmic method been followed rather than standard investigations the number of patients following each route in the flow chart would have been as shown in parentheses in the figure and the ultimate diagnoses as shown in table V. In 17 cases the

TABLE $\mathrm{v}-$ Algorithmic results compared with urodynamic diagnoses

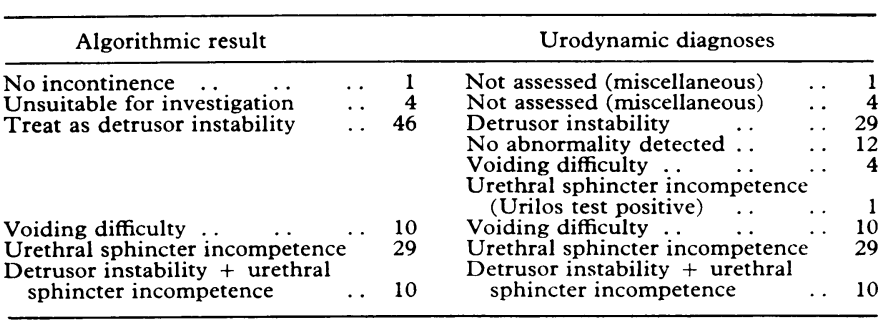

diagnoses reached with the two assessments differed (table V). The 12 patients in whom no abnormality was detected by urodynamic assessments complained of frequency, urgency, and urge incontinence. We routinely treat such patients empirically with antispasmodic drugs, and their management would not therefore have been substantially affected. The one patient with incompetence of the urethral sphincter diagnosed by Urilos, who would have been overlooked by the algorithm, was treated by colposuspension. Of the four patients with voiding difficulties, three were treated for their major complaints: two with stress incontinence by oestrogens, and one with straining to void by urethrotomy; the fourth, with second-degree uterovaginal prolapse, was treated by a ring pessary. Thus from a diagnostic point of view the algorithm gave an accuracy of $83 \%$; in determining treatment the two methods corresponded in $95 \%$ of cases. In addition, in 61 patients the assessment would have been limited to history, physical examination, and midstream urine culture. Invasive procedures would have been carried out in only 39 patients.

\section{Discussion}

The unreliability of the bladder in signalling evidence of disease in young patients has been emphasised by many authors. It would be surprising if the same were not true of the aging bladder, in view of the frequent coexistence of communication difficulties; our findings certainly support this suggestion. Eastwood $^{7}$ made the same point and concluded that urodynamic studies are of value in certain presenting complaints including women with stress incontinence and chronic retention with overflow. Our findings suggest that, based on clinical methods alone, patients may be separated with acceptable accuracy into three categories: "treat as detrusor instability" (including hypersensitive bladders, a few minor voiding difficulties, and patients without demonstrable urodynamic abnormality); major voiding difficulties; and incompetence of the urethral sphincter with or without detrusor instability. The use of supine cystometry in the last group allows further separation. Indeed, the only significant distinction which we feel is not made by this method of assessment is that between voiding difficulties due to detrusor hypotonia and urethral obstruction. Though theoretically this may allow a more rational choice of treatment between the use of cholinergic agents and urethrotomy, we currently decide the mode of treatment largely on clinical grounds. In patients with major voiding difficulties we prefer urethrotomy ${ }^{8}$ regardless of aetiology and find little place for cholinergic agents, particularly in the elderly.

We accept that there may be many contributory factors in the breakdown of continence, and would certainly advocate individualised assessment and treatment. ${ }^{9}$ Nevertheless, we think that with a simple flow plan as outlined here urodynamic assessment may be restricted without appreciable loss of diagnostic accuracy or benefit to the patient.

We are grateful to the British Foundation for Age Research, who generously funded one of us (PH). We also acknowledge Professors A E Bennett and P Millard for helpful discussions during this work, and Sisters Christine Norton and Morag MacDougall for their help in assessing patients.

\section{References}

${ }^{1}$ Milne JS. Prevalence of incontinence in the elderly age groups. In Willington FL, ed. Incontinence in the elderly. London: Academic Press, 1976:9.

2 Stanton SL, Cardozo LD. Surgical treatment of incontinence in elderly women. Surg Gynecol Obstet 1980;150:555-7.

${ }^{3}$ Walter S, Vejlsgaard R. Diagnostic catheterisation and bacteriuria in the female with urinary incontinence. $B r \mathcal{F}$ Urol 1978;50:106-8.

${ }^{4}$ Cardozo LD, Stanton SL, Bennett AE. Design of a urodynamic questionnaire. Br F Urol 1978;50:269-74.

${ }^{5}$ Assmussen $M$, Ulmsten U. Simultaneous urethro-cystometry with a new technique. Scand $\mathcal{F}$ Urol Nephrol 1976;10:7-11.

${ }^{6}$ Stanton SL, Ritchie D. Urilos: the practical detection of urine loss. Am $\mathcal{f}$ Obstet Gynecol 1977;124:461.

${ }^{7}$ Eastwood HDH. Urodynamic studies in the management of urinary incontinence in the elderly. Age Ageing 1979;8:41-8.

${ }^{8}$ Stanton SL, Hilton P, Cardozo LD, Annan H. Internal urethrotomy in the management of impaired voiding in the female. Proceedings of 22nd British congress of obstetrics and gynaecology, 1980.

9 Norton CS. Assessing incontinence. Nursing 1980;1:789-91.

10 Bates P, Bradley WE, Glenn E, et al. The standardisation of terminology of lower urinary tract function. $\mathcal{F}$ Urol 1979;121:551-4.

(Accepted 8 fanuary 1981) 